\section{A RAPID AND SIMPLE SCREENING METHOD FOR HIV-1 PROTEASE INHIBITORS USING RECOMBINANT Escherichia coli}

\author{
Rei Kaneto, IKuo Kojima, \\ Norio SHibamoto, Hiroshi Nishida, \\ Rokuro OKamoto, Hisayoshi AKagawa ${ }^{\dagger}$ \\ and SATOSHI Mizuno ${ }^{\dagger}$
}

Central Research Laboratories, Mercian Corporation, 4-9-1 Johnan, Fujisawa 251, Japan

${ }^{\dagger}$ National Institute of Health, 1-23-1 Toyama, Shinjuku-ku, Tokyo 162, Japan

(Received for publication December 15, 1993)

Extensive efforts have been made to develop anti-HIV drugs from potential HIV-1 protease inhibitor ${ }^{1,2)}$ since the protease inhibitors have been proven to produce immature and non-infectious viruses $^{3,4)}$. In order to find HIV-1 protease inhibitors and study the kinetics of inhibition of the protease, many assay methods have been devised using the protease produced by genetic engineering techniques. These assay methods have used a variety of substrates such as peptides analogous to the natural polyprotein substrate of HIV-1 with chromogenic, fluorometric, or radiometric modifications ${ }^{5 \sim 8)}$, or a fused protein composed of peptides recognized by its specific monoclonal antibody ${ }^{9}$.

This report deals with:

i) construction of a recombinant plasmid carrying the chemically-synthesized HIV-1 protease gene and its successful expression in Escherichia coli;

ii) subsequent establishment of a screening system for HIV-1 protease inhibitors from microbial metabolite origin by using the expressed protease and a peptide analogous to one of the HIV-1 polyproteins; and

iii) a novel screening system of naturally-occurring protease inhibitors by using $E$. coli carrying the recombinant plasmid.

Finally, a comparison of the two screening systems is made and their advantages are discussed.

A DNA fragment carrying synthetic HIV-1 protease was obtained from plasmid BBG 40 (British Biotechnology Laboratory), inserted into an expression vector $\mathrm{pKP} 1500$, and expressed in $E$. coli KP $3998^{10}$ ). The construction of a recombinant plasmid pMAK 105 is illustrated in Fig. 1. The HIV-1 protease-coding fragment was excised from the
BBG 40 by a double digestion with EcoRI and HindIII, and amplified by PCR using 17-mer primer (primer 1: 5'-TATAGAATTCTATGCCG-3') and 16-mer primer (primer 2: 5'-ATATAAGCTTTTACTA- $3^{\prime}$ ). The primers 1 and 2 were designed to meet the following conditions: Original restriction sites, EcoRI and HindIII, could be changed into HindIII and EcoRI, respectively, so that the protease gene could be inserted in a proper orientation into the expression vector; and at the same time, with the primer 1, 11-base pairs could be retained between the plausible $\mathrm{SD}$ sequence (-AGGA-) of the pKP1500 and the initiation codon (-ATG-) of the protease gene for a higher rate of transcription on the resulting plasmid. The PCR product was digested with the two restriction endonucleases, purified, and ligated to pKP1500 to construct the plasmid pMAK 105. The synthetic HIV-1 protease gene was located down-stream from the tac promoter, thus making it possible for the protease gene to be expressed upon induction by isopropyl- $\beta$-thiogalactopyranoside (IPTG). The HIV-1 protease was partially purified from the protease-expressed E. coli by a modified methed of STRICKLER et al. ${ }^{11}$.

The HIV-1 protease activity was determined by using the heptapeptide as a substrate (Ser-Gln-AsnTyr-Pro-Ile-Val), which mimics the cleavage site of the polyprotein (p17/p24) as it originated in HIV-1. The reaction mixture consists of: $100 \mathrm{mM}$ of MES (pH 5.5); $0.2 \mathrm{mM}$ of the peptide substrate; $2.0 \mathrm{M}$ of $\mathrm{NaCl}$; and the partially purified protease. The reaction was performed at $37^{\circ} \mathrm{C}$ for 20 minutes, and terminated by exposure in boiling water for 3 minutes; and the reaction mixture was centrifuged at $12,000 \mathrm{rpm}$ for 5 minutes, and the supernatant was subjected to reverse phase HPLC for quantification of the remaining undigested peptide. An ODS-120T column $(0.6 \times 15 \mathrm{~cm}$, Tosoh) was equilibrated in $23 \%$ acetonitrile and $0.1 \%$ TFA at a flow rate of $1.0 \mathrm{ml} / \mathrm{minute}$. The effluent was monitored by photometric absorbance at $214 \mathrm{~nm}$. Normally, the undigested peptide was eluted at a retention time of 6.0 minutes. We observed that the substrate was digested at the same site as expected from the literature ${ }^{5)}$, thus confirming that the HIV-1 protease was correctly expressed in $E$. coli (Fig. 2).

The enzyme unit (U) was defined as the amount of the enzyme preparation which cleaves $1 \mathrm{mmol}$ of the substrate for 1 minute: One $\mathrm{ml}$ of the cell lysate prepared in this study contained approximately $15 \mathrm{U}$ of the enzyme. Subsequently, the assay system (called HPLC method hereafter) was established to 
Fig. 1. Construction of HIV-1 protease expression vector, pMAK 105.
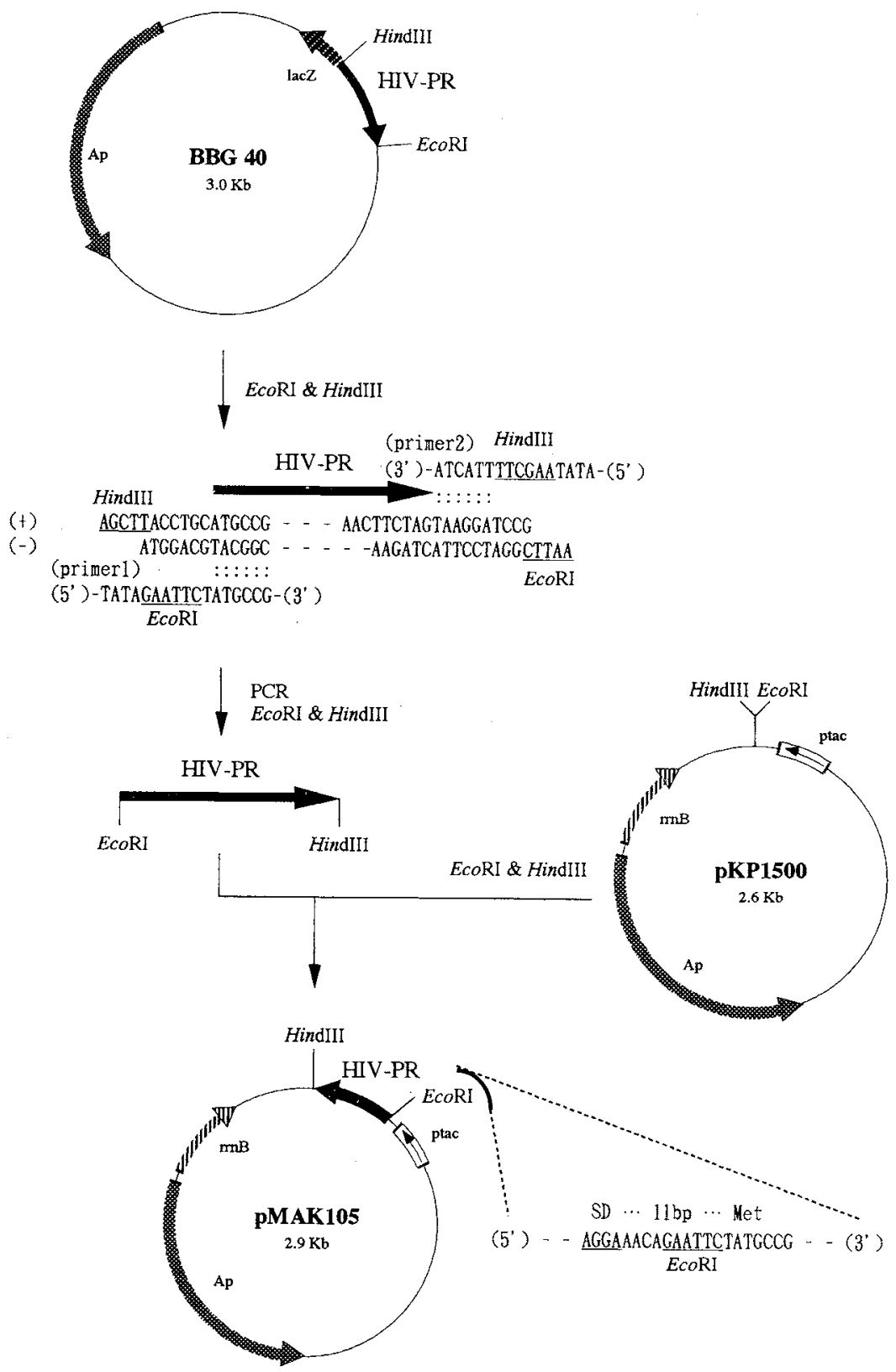

find protease inhibitors from microbial metabolites: The reaction condition was the same as described above except that $0.24 \mathrm{U}$ of the enzyme preparation and $4 \mu \mathrm{l}$ of a test microbial culture were contained in $40 \mu \mathrm{l}$ of the reaction mixture. Inhibition rate was calculated by measuring decrease of peak areas derived from the heptapeptide on the HPLC chromatograms as seen in Fig. 2. With this screening system, we isolated a new HIV-1 protease inhibitor,
Mer-N5075A, as reported previously ${ }^{12)}$.

During the expression study, we found that the growth of the recombinant $E$. coli was inhibited by the protease expressed within the cells. The $E$. coli cells $\left(1 \times 10^{4} \mathrm{CFU} / \mathrm{ml}\right)$ were incubated at $37^{\circ} \mathrm{C}$ for 18 hours in the medium consisting of: $3.2 \%$ glucose, $1.0 \%$ yeast extract (Difco), and $0.5 \% \mathrm{NaCl}(\mathrm{pH} 7.2)$ in the presence or the absence of $0.01 \mathrm{mM}$ of IPTG. The cell growth was monitored by photometric 
Fig. 2. Heptapeptide digestion with cell lysate prepared from $E$. coli carrying pMAK 105 .
(a) Before reaction.
S: heptapeptide (Ser-Gln-Asn-Tyr-Pro-Ile-Val).
(b) After reaction. S: heptapeptide (Ser-Gln-Asn-Tyr-Pro-Ile-Val);
Pl (Pro-Ile-Val).

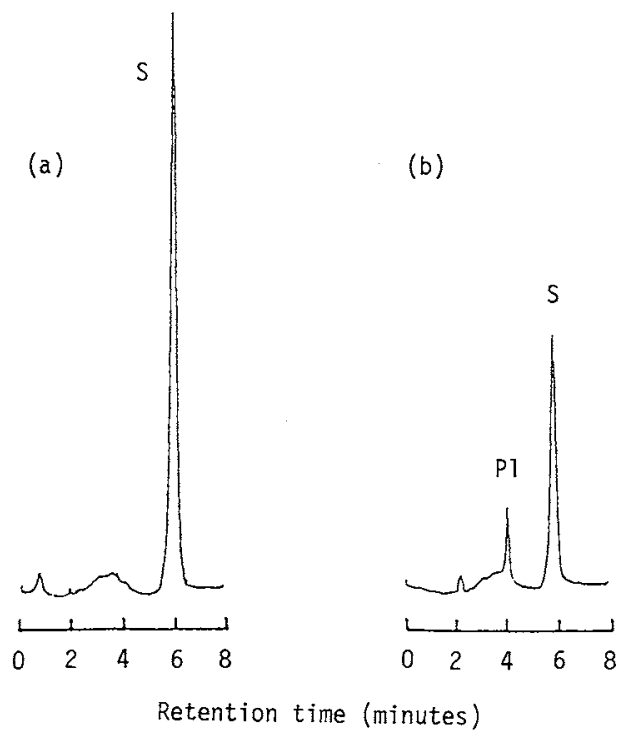

measurement at $630 \mathrm{~nm}$. The addition of IPTG caused a strong growth inhibition in the pMAK105bearing $E$, coli cells, but did not in both pKP1500-bearing cells and the $E$. coli alone (Table 1). The results suggested that the expressed HIV-1 protease was lethal to the host cells presumably by cleaving their intracellular proteins. A similar observation was reported as well ${ }^{13}$.

It was expected that if some HIV-1 protease inhibitor successfully penetrated cells and inhibited effectively the intracellularly-expressed protease, the cells could grow normally in the presence of such a protease inhibitor. A highly-specific HIV-1 protease inhibitor, Ro31-8959'), was used to examine this $E$. coli harboring pMAK 105 was incubated under the same conditions as described above except for the addition of increasing concentrations of the inhibitor. Table 2 shows that growth of the host cells in the presence of IPTG improved as the concentration of the inhibitor increased. The results indicated that the compound was effective in inhibiting HIV-1 protease activity in those $E$. coli cells. In addition, the similar results were obtained with the known protease inhibitors, pepstatin and $\alpha$-MAPI at higher concentrations. It was therefore demonstrated that HIV-1 protease inhibitors could
Table 1. Effect of plasmid, pKP1500 and pMAK105, on growth of E. coli KP3998.

\begin{tabular}{lcc}
\hline \multirow{2}{*}{ Plasmid } & \multicolumn{2}{c}{ OD 630 nm } \\
\cline { 2 - 3 } & - IPTG & + IPTG \\
\hline No plasmid & 0.489 & 0.492 \\
pKP1500 & 0.479 & 0.476 \\
pMAK 105 & 0.493 & 0.116 \\
\hline
\end{tabular}

Table 2. Effect of Ro31-8959 on growth of $E$. coli KP3998.

\begin{tabular}{ccc}
\hline $\begin{array}{c}\text { Concentration of } \\
\text { Ro31-8959 } \\
(\mu \mathrm{M})\end{array}$ & -IPTG & OD 630 nm \\
\cline { 2 - 3 } & 0.470 & 0.113 \\
0 & 0.461 & 0.159 \\
0.13 & 0.472 & 0.300 \\
1.3 & 0.476 & 0.459 \\
\hline
\end{tabular}

Table 3. Comparison of $\mathrm{IC}_{50}$ values of protease inhibitors by OD and HPLC methods.

\begin{tabular}{lcc}
\hline & \multicolumn{2}{c}{$\mathrm{IC}_{50}$} \\
\cline { 2 - 3 } Protease & $\begin{array}{c}\text { OD method } \\
(\mu \mathrm{M})\end{array}$ & $\begin{array}{c}\text { HPLC method } \\
(\mathrm{nM})\end{array}$ \\
\hline & 1.3 & 3.0 \\
Ro31-8959 & $>100$ & 400 \\
Pepstatin & $>100$ & 1,300 \\
$\alpha$-MAPI & \\
\hline
\end{tabular}

be screened by photometrically monitoring the growth difference of the recombinant $E$. coli in the presence and the absence of IPTG (called OD method hereafter).

Table 3 shows the results of comparison of $\mathrm{IC}_{50}$ values of the three protease inhibitors with both the OD and the HPLC methods. Ro31-8959 was proven to be a specifically-active inhibitor, however, the OD method required a 430-fold higher concentration of the inhibitor than the HPLC method: One of the possible reasons for this is due to a poor penetration of the inhibitor into $E$. coli. Similar results were obtained with pepstatin and $\alpha$-MAPI.

Although the OD method needs a higher concentration of test compounds, it seems to have the following advantages: high throughput; moderate cost; and high potential to identify low-molecular weight inhibitors. In our current screening the OD and the HPLC methods have been employed as primary and secondary screenings, respectively. As a result, we have isolated several potent HIV-1 protease inhibitors form microbial metabolites, 
which will be published elsewhere.

\section{Acknowledgments}

We wish to thank Drs. T. MiKI and T. IMoto at the Kyusyu University for their generous gift of E. coli KP3998 and plasmid, pKP1500. Thanks are also given to Drs. N. RoBerts and C. STRong at Roche Research Center, Roche Products Ltd., Welwyn Garden City, UK, for their kind gift of Ro31-8959. This work was partly supported by Japan Health Science Foundation.

\section{References}

1) Roberts, N. A.; J. A. Martin, D. Kinchington, A. V. Broadhurst, J. C. Craig, I. B. Duncan, S. A. Galpin, B. K. Handa, J. Kay, A. KRÖHN, R. W. Lambert, J. H. Merrett, J. S. Mills, K. E. B. Parkes, S. Redshaw, A. J. Ritchie, D. L. TAYlor, G. J. Thomas \& P. J. Machin: Rational design of peptide-based HIV protease inhibitors. Science 248: $358 \sim 361,1990$

2) KempF, D. J.; D. W. Norbeck, L. Codacovi, X. C. Wang, W. E. Kohlbrenner, N. E. Wideburg, D. A. Paul, M. F. Knigge, S. Vasavanonda, A. Craig-Kennard, A. Saldivar, W. Rosenbrook, Jr., J. J. Clement, J. J. Plattiner \& J. Erickson: Structure-based, $C_{2}$ symmetric inhibitors of HIV protease. J. Med. Chem. 33: 2687 2689, 1990

3) Seelmeier, S.; H. Schmidt, V. Turk \& K. Helm: Human immunodeficiency virus has an aspartic-type protease that can be inhibited by pepstatin A. Proc. Natl. Acad. Sci. U.S.A. 85: 6612 6616, 1988

4) DeBouck, C.: The HIV-1 protease as a therapeutic target for AIDS. AIDS Res. Hum. Retroviruses 2: $153 \sim 164,1992$

5) Darke, P. L.; R. F. NutT, S. F. BRady, V. M. Garsky, T. M. Ciccarone, C. T. LeU, P. K. Lumma, R. M. Freidinger, D. F. Verber \& I. S. SIGAL: HIV-1 protease specificity of peptide cleavage is sufficient for processing of gag and pol polyproteins. Biochem. Biophys. Res. Commun. 156: $297 \sim 303,1988$
6) Tomaszek, T. A.; V. W. Magaard, H. G. Bryan, M. L. MoORE \& T. D. MeEK: Chromophoric peptide substrates for the spectrophotometric assay of HIV-1 protease. Biochem. Biophys. Res. Commun. 168: $274 \sim 280,1988$

7) Tamburini, P. P.; R. N. Dreyer, J. Hansen, J. Letsinger, J. Elting, A. G. Willse, R. Dally, R. Hanko, D. Osterman, M. E. Kamarck \& H. Y. WARREN: A fluorometric assay for HIV-protease activity using high-performance liquid chromatography. Anal. Biochem. 186: 363 368, 1990

8) Hyland, L. J.; B. D. Dayton, M. L. Moore, A. Y. Shu, J. R. HeYs \& T. D. MeEK: A radiometric assay for HIV-1 protease. Anal. Biochem. 188: 408 415, 1990

9) Sarubbi, E.; M. L. Nolli, F. Andronico, S. Stella, G. Saddler, E. Selva, I. A. Siccard \& M. Denaro: A high throughput assay for inhibitors of HIV-1 protease: screening of microbial metabolites. FEBS Lett. 279: 265 269, 1991

10) Miki, T.; T. Yasukochi, H. Nagatani, M. Furuno, T. Orita, H. Yamada, T. Imoto \& T. Horiuchi: Construction of a plasmid vector for the regulatable high level expression of eukaryotic genes in Escherichia coli: an application to overproduction of chicken lysozyme. Protein Engineering 4: 327 332, 1987

11) Strickler, J. E.; J. Gorniak, B. Dayton, T. Meek, M. Moore, V. Maggard, J. Malinwski \& C. DEBOuCK: Characterization and autoprocessing of precursor and mature forms of human immunodeficiency virus type 1 (HIV-1) protease purified from Escherichia coli. Proteins Struct. Funct. Genet. 6: $139 \sim 154,1989$

12) Kaneto, R.; H. Chiba, K. Dobashi, I. Kojima, K. Sakai, N. Shibamoto, H. Nishida, R. Okamoto, H. AkaGawa \& S. Mizuno: Mer-N5075A, a potential HIV-1 protease inhibitor, produced by Streptomyces chromofuscus. J. Antibiotics 46: 1622 1624, 1993

13) Hostomsky, Z.; K. Appelt \& R. C. Ogden: High level expression of self-processed HIV-1 protease in Escherichia coli using a synthetic gene. Biochem. Biophys. Res. Commun. 161: 1056 1063, 1989 